\title{
Tumor-infiltrating lymphocytes in tissue material combined with systemic lymphocyte inflammation in patients with colorectal cancer
}

\author{
KATARZYNA JAKUBOWSKA ${ }^{1}$, MARIUSZ KODA ${ }^{2}$, MAŁGORZATA GRUDZIŃSKA ${ }^{2}$, \\ KAROLINA LOMPERTA ${ }^{1}$ and WALDEMAR FAMULSKI ${ }^{3}$ \\ ${ }^{1}$ Department of Pathomorphology, Comprehensive Cancer Center, 15-027 Bialystok; \\ Departments of ${ }^{2}$ General Pathomorphology and ${ }^{3}$ Medical Pathomorphology, \\ Medical University of Bialystok, 15-269 Bialystok, Poland
}

Received June 22, 2020; Accepted February 11, 2021

DOI: $10.3892 / \mathrm{mco} .2021 .2259$

\begin{abstract}
The efficacy of cancer immunotherapy has been actively explored in the treatment of various malignant neoplasms of the gastrointestinal tract. In light of recent reports, the present study aimed to investigate the combination of the absolute lymphocyte count (ALC), percentage of tumor-infiltrating lymphocyte (TILs) and tumor progression status in patients with colorectal cancer (CRC) who underwent surgery. The medical records of 160 patients diagnosed with CRC were retrospectively reviewed. TILs were determined as a percentage of mononuclear inflammatory cells in the total intratumoral or stromal area as determined in five high power fields (magnification, x200-400), at the invasive front and in the centre of the tumour. Blood samples were obtained within 3 days prior to and 7 days following the surgical treatment. The assessment of the TIL percentage was performed in the tissue at the invasive front and in the centre of the primary tumour mass in combination with the determination of ALC in whole blood samples. The samples were obtained prior to and after surgery from patients with CRC, and the tumour progression status was also assessed (TILs/ALC/tumour progression status). A significant association was observed between the percentage of TILs in the main mass of tumour and the tumour size $(\mathrm{P}=0.031)$, the $\mathrm{pT}$ stage $(\mathrm{P}=0.049)$ and the incidence of necrosis $(\mathrm{P}=0.037)$ following surgery. The histological type was associated with the evaluated combined parameters prior to surgery $(\mathrm{P}=0.046)$. Lymph node pouch invasion was associated with TILs at the invasive front of tumour and with ALC prior to and after surgery $(\mathrm{P}=0.006$ and
\end{abstract}

Correspondence to: Dr Katarzyna Jakubowska, Department of Pathomorphology, Comprehensive Cancer Center, 12 Ogrodowa Street, 15-027 Bialystok, Poland

E-mail: kathian@wp.pl

Key words: tumor-infiltrating lymphocytes, lymphocyte count, whole blood samples, colorectal cancer
$\mathrm{P}=0.037)$. Furthermore, the data indicated that the percentage of TILs located on the invasive front and centre of the tumour, and the ALC prior to and following surgery correlated with the treatment status $(\mathrm{P}=0.032, \mathrm{P}=0.018, \mathrm{P} \leq 0.001$ and $\mathrm{P} \leq 0.001)$. A significant association was noted between eight features and evaluated combined parameters following surgery. These included the tumour size $(\mathrm{P}=0.021)$, TNM stage $(\mathrm{P}<0.001)$, tumour deposits $(\mathrm{P}=0.001)$, incidence of necrosis $(\mathrm{P}=0.042)$ and lymph node metastasis $(\mathrm{P}<0.001)$. Furthermore, the degree of invasion of venous $(\mathrm{P}<0.001)$, lymphatic $(\mathrm{P}<0.001)$ and perineural $(\mathrm{P}<0.001)$ sites was also significantly associated with TILs, ALC obtained after surgical treatment and tumor progression status. The data demonstrated that local and systemic chronic inflammation was associated with tumour progression in patients with CRC.

\section{Introduction}

Cancer immunotherapy has been actively explored in the treatment of various malignant neoplasms of the gastrointestinal tract $(1,2)$. Recently, nanotechnology-mediated delivery approaches have attracted considerable attention in colorectal cancer (CRC) immunotherapy. Nanoparticle-based immunotherapy exhibits higher specificity and efficacy in comparison with conventional immunotherapy (3). Those immune-related transmitters can locally deliver immune components to the antigen presenting cells with high efficiency and modulate the tumor immune microenvironment. In addition, they act as an adjuvant that can boost immune reactions to antigens (4). CRC is a heterogeneous group of malignant lesions with different types of immune responses (5). Previous studies have focused on the morphological assessment and molecular changes that occur during $\mathrm{CRC}$, which includes mutational status and chromosomal instability, somatic copy number variation, immune infiltration and metabolic regulation. Based on this evidence CRC can be divided into five groups of tumors as follows: Microsatellite instability-associated, immune-associated, canonical, metabolic and mesenchymal (6). The proposed division of cancerous tumors is closely associated with tumor stage and survival time. Recent studies have shown that patients 
with a high status of microsatellite instability respond better to immunotherapy (7). Therefore, systemic immune response is associated with infiltration of immune cells in CRC tumors, which appear to be separated from the tumor microenvironment (8). The immune cells infiltrating CRC tumors are macrophages, dendritic cells, neutrophils and lymphocytes. Immunotherapy is focused on the ability of lymphocytes to infiltrate the cancerous tissue. It has been shown that lymphocytes infiltrates exhibit considerable variation with regard to their biological characteristics in the different parts of the tumor (9). Laghi et al (9) demonstrated that the infiltrate of $\mathrm{T}$ cells in the invasive margin of CRC tumors could improve disease prognosis compared with cells examined at the center of the tumor. In addition, Bindea et al (10) indicated that the amount of $\mathrm{T}$ cells present in the tumor was decreased over time, while the number of B cells and innate immune cells was increased. Moreover, local immune response in the tumor tissue was closely associated with systemic exposure to circulating cancer cells in the bloodstream. Therefore, the analysis of hematological parameters appears to be an important indicator of immune response to cancer. Currently, several studies using hematological factors, such as absolute lymphocyte count (ALC), absolute neutrophil count, neutrophil-to-lymphocyte ratio (NLR) and platelet-to-lymphocyte ratio (PLR) have been conducted (11-13). Tanio et al (11) indicated that the combined absolute number of lymphocytes, monocytes and neutrophils in the preoperative whole blood can be a useful prognostic factor in CRC patients (11). Kozak et al (12) proposed that the elevated NLR independently predicts worse overall survival in patients with CRC. In addition, Yang et al (13) demonstrated that an increased PLR value was associated with poor overall survival. In light of these reports, the present study aimed to investigate the combination of the ALC, tumor-infiltrating lymphocyte (TIL) percentage and tumor progression status in patients with CRC who underwent surgery.

\section{Patients and methods}

Patients and tissue specimens. A total of 160 patients who were diagnosed with CRC were retrospectively reviewed (96 male, 64 female; median age, 72 years). In the present study, the paraffin-embedded tissues were obtained from the Comprehensive Cancer Centre between April 2014 and December 2016. The patients who were diagnosed with CRC underwent surgery in the Division of Surgical Oncology. All of the tissue samples were processed by an identical dissection protocol. The tissues obtained from surgery were fixed in $4 \%$ buffered formalin and subsequently small sections of tissues were embedded in paraffin. The sections ( $4 \mu$ m-thick) were cut from paraffin blocks and stained with haematoxylin and eosin (H\&E). The slides were deparaffinised in an oven at $60^{\circ} \mathrm{C}$ for $5 \mathrm{~min}$. Subsequently, the slides were rehydrated in xylene (three washes) and graded ethanol (100, 95, 85 and $75 \%$ ). Histological assessment was performed by two pathologists, which were blinded to the study protocol. The following parameters were recorded from each patient: Type of tumour growth, Tumour-Node-Metastasis (TNM) stage, tumour size, histological type, percentage of mucinous components and grade of malignancy. The clinical stage of CRC was evaluated according to the TNM classification (14). Venous, perineural and lymphatic invasion (the number of resected and invaded lymph nodes, the presence of micro- and macro-metastases, invasion of the pouch lymph node, presence of distant metastases and the size of metastases) were also assessed. The deposits of cancer (their number and size) were also included (15).

The patients enrolled in the present study presented similar symptoms. The most common symptoms were abdominal pain, vomiting, rectal bleeding, constipation or diarrhoea. The medical history demonstrated that some patients suffered from hypertension, diabetes (type II), coronary heart disease or osteoarthritis. However, none of the patients had received anti-inflammatory or immunosuppressive therapy. All of the patients underwent routine diagnostic tests prior to surgery (blood tests, electrocardiography and spirometry). The diagnostic examinations, such as a chest computerized tomography and chest X-ray were utilized to identify CRC distal metastasis. The patients with neoplasm in the rectum received preoperative therapy $(n=53)$ : Radiotherapy $(n=39)$, chemotherapy $(n=7)$ and radio-chemotherapy $(n=7)$. The radiation dose used was $25 \mathrm{~Gy}$, in fractions of 5 Gy during one week in the pelvic area. According to the Response Evaluation Criteria in Tumours (16), the response to preoperative therapy was evaluated. A total of 26 patients were recruited with a stable disease and 27 patients exhibited partial response.

The inclusion criteria were as follows: i) Pathologically confirmed CRC; ii) treatment with radical resection; and iii) lack of anti-inflammatory therapy. The exclusion criteria were the following: i) Incomplete clinicopathological and follow-up data; and ii) presence of haematological disorders, such as anaemia.

The present study was performed in conformity with the Declaration of Helsinki for Human Experimentation and the protocol was approved by the Bioethics Committee of the Medical University of Bialystok (no. R-I-002/353/2016).

Assessment of the percentage of TILs in CRC tissues. The analysis of TILs was described in our previous study (17). Briefly, tissue material obtained from routine histopathological diagnosis was stained with H\&E and used to assess the TIL populations located in the tumor stroma at the invasive front and centre of the tumour by light microscopy (magnification, x200-400; Leica DM6 B; Leica Microsystems, Inc.). The analysis was evaluated by two independent pathologists who were blinded to the clinical information of the study. TILs in the stroma were identified according to recommendations by the International TILs Working Group, 2014 (18). They were determined as a percentage of mononuclear inflammatory cells in the total intratumoral or stromal area as counted in 5 high power fields (HPF; magnification, x200-400), at the invasive front and in the centre of the tumour, with the exception of tumour areas with crush artefacts, necrosis or regressive hyalinization. The invasive front of the tumour was defined as the percentage of most progressed cancer cells on the advanced edge of the tumour. For statistical analysis, the percentage of stromal TILs was scored as follows: 1 , weak (0-10\% stromal TILs); 2, moderate (20-40\% stromal TILs); and 3, strong (50-90\% stromal TILs). The study population was divided into two groups based on the stromal TIL score as follows: 1, score 1; and 2, score 2 or 3. Representative images of TILs are shown in Fig. 1.

Blood sample examination. Blood samples were obtained within 3 days prior to and 7 days following surgical treatment. 

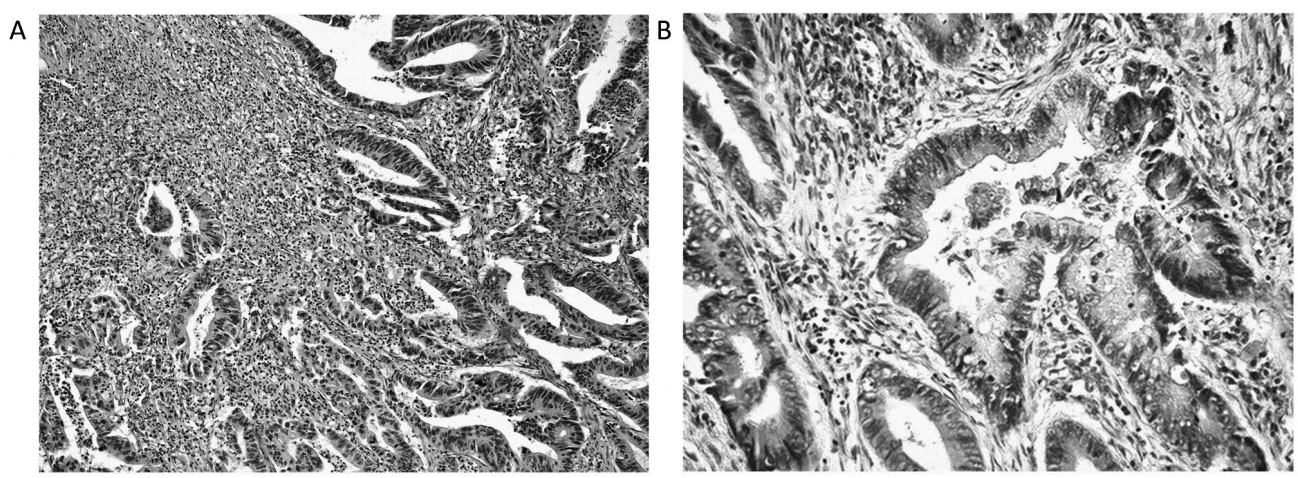

Figure 1. Representative images of complex of tumor-infiltrating lymphocytes (A) at the invasive front and (B) in the center of resected colorectal cancer tissue (H\&E staining; original magnification, x100).

Venous blood samples were also obtained from 42 healthy control subjects (female-21, male-21; mean age 45 years old; min-max 25-65 years old). The differential white blood cell count was counted using an XN-1000 automated haematology analyzer (Sysmex America, Inc.). Normal total lymphocyte count ranges were between 0.90 and $4.00 \times 10^{3}$ cells $/ \mu 1$ (mean $2.25 \times 10^{3}$ cells $\left./ \mu 1\right)$. The total lymphocyte count in CRC patients ranged from 0.47 to $4.06 \times 10^{3}$ cells $/ \mu 1$ (mean $1.05 \times 10^{3}$ cells $/ \mu 1$ ).

Combination of TIL percentage and ALC. The percentage of TILs was examined in the CRC tissue at the invasive front and centre of the primary tumour mass in combination with the ALC and in whole blood samples obtained prior to and following surgery from patients with CRC. The classification of the immune response system included: i) TILs at the invasive front and ALC prior to surgery; ii) TILs in the centre of the tumour mass and ALC prior to surgery; iii) TILs at the invasive front and ALC following surgery, iv) TILs in the centre of the tumour mass and ALC following surgery. All groups included 4 subgroups: i) High TILs (moderate or strong stromal TILs) and high $\operatorname{ALC~}\left(\geq 4.0 \times 10^{3}\right.$ cells $\left./ \mu 1\right)$; ii) high TILs (moderate or strong stromal TILs) and low ALC $\left(\leq 0.9 \times 10^{3}\right.$ cells $\left./ \mu 1\right)$; iii) low TILs (weak stromal TILs) and high $\operatorname{ALC~(~} \geq 4.0 \times 10^{3}$ cells $\left./ \mu 1\right)$; iv) low TILs (weak stromal TILs) and low ALC $\left(\leq 0.9 \times 10^{3}\right.$ cells $\left./ \mu 1\right)$.

In the present study, the combination of TIL percentage and ALC was also examined with regard to the tumor progression status (TILs/ALC/tumour progression status). The tumour progression status was determined on the basis of 3 parameters as follows: i) Lymphatic vessel invasion; ii) lymph node involvement and iii) distant metastasis. Based on the tumour progression status the study population was divided into 3 groups as follows: i) patients with local disease; ii) patients with lymphatic vessel invasion and positive lymph node status without distant metastasis; iii) patients that exhibited cancer cell invasion to all the aforementioned structures. The local and systemic response of lymphocytes prior to and following surgical treatment was investigated. Taken together, the patients were divided into 4 groups as follows: i) Negative status of tumour progression with high percentage of TILs at the invasive front and in the centre of the primary tumour mass and high ALC, ii) negative status of tumour progression with high percentage of TILs as the invasive front and in the centre of the primary tumour mass and low ALC, iii) positive status of tumour progression (group 2 or 3) with high percentage of TILs at the invasive front and in the centre of the primary tumour mass and high ALC and iv) positive status of tumour progression (group 2 or 3) with high percentage of TILs at the invasive front and in the centre of the primary tumour mass and high ALC.

Statistical analysis. All calculations were performed using the statistical software STATISTICA 13.0 (StatSoft, Inc.). The enumeration data of examined parameters were analysed using the $\chi^{2}$ test. The comparisons among multiple groups (examined parameters and clinicopathological features) were analysed using one-way ANOVA. Fisher's Least Significant Difference post hoc test was used to analyze multiple comparisons of TILs, ALC, progression status and histopathological factors following the ANOVA test (data not shown). Tukey's test was used to compare more than three groups. $\mathrm{P}<0.05$ was considered to indicate a statistically significant difference.

\section{Results}

Patient characteristics and distribution of the combination index including TIL percentage and ALC in CRC patients. The median age was 67.5 years (range, 32 to 88 years) and $60 \%$ of the patients were male. The rectum was the most common tumour location (51.25\%). The pathological staging was the following: Stage I in $1.88 \%$ of patients, stage II in $38.75 \%$ of patients, stage III in $56.88 \%$ of patients and stage IV in $2.5 \%$ of patients. The patients developed adenocarcinoma $(81.25 \%)$ more frequently than mucinous CRC $(18.75 \%)$. The distribution of TILs was evaluated based on several factors, such as invasion of cancer cells, distant metastasis or status of tumour progression. The data indicated that the distribution of the combination index including TIL percentage and ALC differed significantly among the groups (Table I). However, statistical significance was not obtained for the distribution of the TILs/ALC/progression tumour status (Table II).

Correlation of the combination index including TIL percentage and ALC with the clinicopathological parameters of CRC patients. The percentage of TILs and the ALC prior to and following surgery were significantly associated with the tumour growth in the main mass (Tables III and IV, $\mathrm{P}=0.001, \mathrm{P}=0.007)$. A significant correlation was observed in the percentage of TILs with the tumour size $(\mathrm{P}=0.031), \mathrm{pT}$ 
Table I. Distribution of the combined parameters of TILs and ALC.

\begin{tabular}{|c|c|c|c|c|c|}
\hline \multirow[b]{2}{*}{ Parameter } & \multicolumn{4}{|c|}{ Groups } & \multirow[b]{2}{*}{ P-value } \\
\hline & $\begin{array}{c}\text { High } \\
\text { TILs/high } \\
\text { ALC, n }\end{array}$ & $\begin{array}{l}\text { High } \\
\text { TILs/low } \\
\text { ALC, n }\end{array}$ & $\begin{array}{c}\text { Low } \\
\text { TILs/high } \\
\text { ALC, n }\end{array}$ & $\begin{array}{c}\text { Low } \\
\text { TILs/low } \\
\text { ALC, n }\end{array}$ & \\
\hline TILs at the invasive front and ALC before surgery & 39 & 116 & 2 & 9 & $<0.001$ \\
\hline TILs at the invasive front and ALC after surgery & 75 & 72 & 4 & 1 & \\
\hline TILs in the main mass of primary tumor and ALC before surgery & 39 & 121 & 2 & 7 & $<0.001$ \\
\hline TILs in the main mass of primary tumor and ALC after surgery & 74 & 69 & 3 & 4 & \\
\hline
\end{tabular}

TILs, tumor-infiltrating lymphocytes; ALC, absolute lymphocyte count.

Table II. Distribution of the TILs/ALC/tumor progression status.

\begin{tabular}{|c|c|c|c|c|c|}
\hline \multirow[b]{2}{*}{ Parameter } & \multicolumn{4}{|c|}{ Groups } & \multirow[b]{2}{*}{ P-value } \\
\hline & $1, \mathrm{n}$ & $2, \mathrm{n}$ & $3, \mathrm{n}$ & $4, \mathrm{n}$ & \\
\hline TILs at the invasive front, ALC and tumor progression status & 12 & 48 & 28 & 72 & 0.164 \\
\hline TILs in the main mass of the primary tumor, ALC and tumor progression status & 29 & 30 & 47 & 54 & \\
\hline
\end{tabular}

TILs, tumor-infiltrating lymphocytes; ALC, absolute lymphocyte count.

stage $(\mathrm{P}=0.049)$ and necrosis percentage $(\mathrm{P}=0.037)$ following surgery. The histological type correlated with the combination index prior to surgery $(\mathrm{P}=0.046)$. Lymph node pouch invasion was associated with the percentage of TILs at the invasive front of the tumour and with ALC prior to and following surgery $(\mathrm{P}=0.006, \mathrm{P}=0.037)$. Moreover, the percentage of TILs exanimated at the invasive front and centre of the tumour, and the ALC prior to and following surgery correlated with the treatment status $(\mathrm{P}=0.032, \mathrm{P}=0.018, \mathrm{P} \leq 0.001, \mathrm{P} \leq 0.001)$. The patients with neoadjuvant therapy (status treatment group 1 and 2) exhibited better local and systemic chronic inflammatory response. Furthermore, no significant difference was observed in the remaining evaluated parameters (Tables III and IV).

Subsequent correlation analysis was performed between different clinical parameters. Specifically, the percentage of TILs, the ALC, the tumour progression status and the clinicopathological features were compared (Table V). The histopathological type, percentage of mucinous component and lymph node pouch invasion correlated significantly with the evaluated combined parameters prior to and following surgery. The growth of the tumour was associated with the percentage of TILs, the ALC and the tumour progression status prior to surgery $(\mathrm{P}=0.037)$. A significant correlation was observed between eight features with evaluated combined parameters following surgery. These were the tumour size $(\mathrm{P}=0.021)$, TNM stage $(\mathrm{P}<0.001)$, tumour deposits $(\mathrm{P}=0.001)$, necrosis $(\mathrm{P}=0.042)$ and lymph node metastasis $(\mathrm{P}<0.001)$. Moreover, the percentage of invasion of venous $(\mathrm{P}<0.001)$, lymphatic $(\mathrm{P}<0.001)$ and perineural $(\mathrm{P}<0.001)$ sites exhibited a significant correlation with the combination index including the percentage of TILs and the ALC. Moreover, no additional correlations were noted between the percentage of TILs and the ALC, the tumour progression status and the remaining clinicopathological parameters. Furthermore, multiparametric analysis was associated with the treatment status for patients who had received preoperative treatment. Moreover, TILs/ALC/tumour progression status and recurrence/prognosis were not statistically significant (data not shown).

\section{Discussion}

Multiple studies have emphasized on the importance of the host immunity during the development of CRC. The local inflammation has been previously measured in the tumour mass of CRC patients following surgical resection $(19,20)$. More specifically, these studies were based on the measurement of $\mathrm{CD}^{+} \mathrm{T}$ cells, $\mathrm{CD}^{+} \mathrm{T}$ cells, and/or $\mathrm{CD} 45 \mathrm{RO}^{+}$memory $\mathrm{T}$ cells that were localized in the invasive front and in the centre of the primary tumour mass. The main finding was that the immune score could be used as a superior predictor of CRC recurrence in everyday practice $(19,20)$. Furthermore, in response to the predictive value of the intensive local inflammation caused by high density TILs, the systemic inflammation is also frequently investigated. It has been shown that systemic inflammatory response is associated with a pro-tumour response and poor prognosis for CRC patients (21).

Recent data have suggested that local and systemic inflammatory response in CRC should be assessed in combination. This type of assessment may affect patient prognosis. Park et al (22) demonstrated a significant role of the density of $\mathrm{T}$ lymphocytes within the cancer cell areas. Moreover, an increased level of modified Glasgow Prognostic Score (mGPS) was noted in patients with mismatch repair-deficient (dMMR) CRC (22). 
Table III. Associations between combined parameters of TILs and absolute lymphocyte count obtained before surgery, and clinicopathological features of patients with CRC $(n=160)$.

\begin{tabular}{|c|c|c|c|c|c|c|c|c|c|c|c|}
\hline \multirow[b]{3}{*}{ Parameter } & \multirow[b]{3}{*}{ No. } & \multicolumn{10}{|c|}{ TILs and absolute lymphocyte count before surgery } \\
\hline & & \multicolumn{5}{|c|}{ Invasive front } & \multicolumn{5}{|c|}{ Main mass } \\
\hline & & $1, \mathrm{n}$ & $2, \mathrm{n}$ & $3, \mathrm{n}$ & $4, \mathrm{n}$ & P-value & $1, \mathrm{n}$ & $2, \mathrm{n}$ & $3, \mathrm{n}$ & $4, \mathrm{n}$ & P-value \\
\hline \multicolumn{12}{|l|}{ Age, years } \\
\hline$<60$ & 40 & 5 & 30 & 0 & 5 & \multirow{2}{*}{0.420} & 5 & 32 & 0 & 3 & \multirow[t]{2}{*}{0.420} \\
\hline$\geq 60$ & 120 & 29 & 69 & 2 & 20 & & 29 & 70 & 2 & 19 & \\
\hline \multicolumn{12}{|l|}{ Sex } \\
\hline Female & 64 & 12 & 41 & 0 & 11 & \multirow[t]{2}{*}{0.696} & 12 & 41 & 0 & 11 & \multirow[t]{2}{*}{0.696} \\
\hline Male & 96 & 22 & 58 & 2 & 14 & & 22 & 61 & 2 & 11 & \\
\hline \multicolumn{12}{|l|}{ Localization } \\
\hline Right-side & 20 & 8 & 11 & 1 & 0 & \multirow[t]{5}{*}{0.407} & 4 & 12 & 1 & 3 & \multirow[t]{5}{*}{0.561} \\
\hline Transverse & 14 & 4 & 4 & 0 & 6 & & 1 & 4 & 0 & 9 & \\
\hline Left-side & 15 & 1 & 5 & 0 & 9 & & 1 & 5 & 0 & 10 & \\
\hline Sigmoid & 29 & 1 & 11 & 0 & 7 & & 8 & 8 & 0 & 13 & \\
\hline Rectum & 82 & 17 & 54 & 1 & 10 & & 16 & 54 & 0 & 12 & \\
\hline \multicolumn{12}{|c|}{ Tumor growth } \\
\hline Expanding & 133 & 28 & 82 & 2 & 21 & \multirow[t]{2}{*}{0.109} & 28 & 82 & 2 & 21 & \multirow[t]{2}{*}{0.001} \\
\hline Infiltrate & 27 & 6 & 17 & 0 & 3 & & 6 & 20 & 0 & 1 & \\
\hline \multicolumn{12}{|c|}{ Tumor size, $\mathrm{cm}$} \\
\hline$<2.5$ & 27 & 6 & 15 & 1 & 5 & \multirow[t]{3}{*}{0.412} & 6 & 17 & 1 & 3 & 0.181 \\
\hline $2.5-5.0$ & 106 & 26 & 63 & 0 & 17 & & 25 & 64 & 1 & 16 & \\
\hline$>5.0$ & 27 & 2 & 21 & 1 & 3 & & 3 & 21 & 0 & 3 & \\
\hline Histological & & & & & & & & & & & \\
\hline Muc & 30 & 4 & 25 & 0 & 1 & 0.322 & 8 & 22 & 0 & 0 & 0.046 \\
\hline Adca & 130 & 30 & 74 & 2 & 24 & & 30 & 79 & 2 & 19 & \\
\hline Mucinous co & & & & & & & & & & & \\
\hline $10-30$ & 15 & 0 & 10 & 0 & 5 & 0.392 & 0 & 10 & 0 & 5 & 0.148 \\
\hline $31-50$ & 15 & 4 & 11 & 0 & 0 & & 4 & 11 & 0 & 0 & \\
\hline TNM stage & & & & & & & & & & & \\
\hline $1+2$ & 73 & 10 & 49 & 1 & 13 & 0.518 & 11 & 53 & 0 & 9 & 0.417 \\
\hline $3+4$ & 87 & 24 & 50 & 1 & 12 & & 23 & 49 & 2 & 13 & \\
\hline Grade of mal & & & & & & & & & & & \\
\hline 2 & 148 & 32 & 93 & 2 & 21 & 0.812 & 32 & 96 & 2 & 18 & 0.482 \\
\hline 3 & 12 & 2 & 6 & 0 & 4 & & 2 & 6 & 0 & 4 & \\
\hline pT stage & & & & & & & & & & & \\
\hline $1+2$ & 65 & 13 & 39 & 1 & 12 & 0.159 & 13 & 41 & 1 & 10 & 0.154 \\
\hline $3+4$ & 95 & 21 & 60 & 1 & 13 & & 21 & 61 & 1 & 12 & \\
\hline Venous invas & & & & & & & & & & & \\
\hline Absent & 113 & 22 & 70 & 1 & 20 & 0.642 & 23 & 73 & 0 & 17 & 0.083 \\
\hline Present & 46 & 12 & 29 & 1 & 4 & & 11 & 29 & 2 & 4 & \\
\hline Lymphatic in & & & & & & & & & & & \\
\hline Absent & 121 & 24 & 75 & 1 & 21 & 0.952 & 24 & 78 & 0 & 19 & 0.961 \\
\hline Present & 38 & 10 & 24 & 1 & 3 & & 10 & 24 & 2 & 2 & \\
\hline Perineural in & & & & & & & & & & & \\
\hline Absent & 143 & 30 & 89 & 2 & 22 & 0.415 & 30 & 92 & 2 & 19 & 0.478 \\
\hline Present & 17 & 4 & 10 & 0 & 3 & & 4 & 10 & 0 & 3 & \\
\hline Lymph node & & & & & & & & & & & \\
\hline Absent & 81 & 16 & 60 & 1 & 4 & 0.350 & 16 & 62 & 1 & 2 & \\
\hline Present & 79 & 18 & 39 & 1 & 21 & & 18 & 40 & 1 & 20 & 0.405 \\
\hline
\end{tabular}


Table III. Continued.

TILs and absolute lymphocyte count before surgery

\begin{tabular}{|c|c|c|c|c|c|c|c|c|c|c|c|}
\hline \multirow[b]{3}{*}{ Parameter } & \multirow[b]{3}{*}{ No. } & \multirow{2}{*}{\multicolumn{5}{|c|}{ Invasive front }} & \multirow{2}{*}{\multicolumn{5}{|c|}{ Main mass }} \\
\hline & & & & & & & & & & & \\
\hline & & $1, \mathrm{n}$ & $2, \mathrm{n}$ & $3, \mathrm{n}$ & $4, \mathrm{n}$ & P-value & $1, \mathrm{n}$ & $2, \mathrm{n}$ & $3, \mathrm{n}$ & $4, \mathrm{n}$ & P-value \\
\hline \multicolumn{12}{|c|}{ Lymph node pouch invasion } \\
\hline Absent & 41 & 17 & 9 & 2 & 13 & \multirow[t]{2}{*}{0.006} & 10 & 5 & 13 & 13 & \\
\hline Present & 39 & 17 & 3 & 0 & 19 & & 14 & 2 & 6 & 17 & 0.775 \\
\hline \multicolumn{12}{|c|}{ Distant metastasis } \\
\hline Absent & 143 & 28 & 91 & 2 & 22 & \multirow{2}{*}{0.916} & 29 & 95 & 1 & 18 & \multirow[t]{2}{*}{0.873} \\
\hline Present & 17 & 6 & 8 & 0 & 3 & & 5 & 7 & 1 & 4 & \\
\hline \multicolumn{12}{|c|}{ Tumor deposits } \\
\hline Absent & 133 & 24 & 84 & 2 & 23 & \multirow[t]{2}{*}{0.565} & 25 & 87 & 1 & 20 & \multirow[t]{2}{*}{0.474} \\
\hline Present & 27 & 10 & 14 & 0 & 3 & & 9 & 14 & 1 & 2 & \\
\hline \multicolumn{12}{|c|}{ Tumor budding } \\
\hline Absent & 94 & 20 & 57 & 1 & 16 & \multirow[t]{2}{*}{0.436} & 20 & 59 & 1 & 14 & \multirow[t]{2}{*}{0.945} \\
\hline Present & 66 & 14 & 42 & 1 & 9 & & 14 & 43 & 1 & 8 & \\
\hline \multicolumn{12}{|l|}{ Necrosis } \\
\hline Absent & 45 & 6 & 29 & 0 & 10 & \multirow[t]{4}{*}{0.632} & 5 & 31 & 1 & 8 & \multirow[t]{4}{*}{0.538} \\
\hline Focal & 61 & 13 & 41 & 0 & 7 & & 13 & 39 & 0 & 9 & \\
\hline Moderate & 36 & 9 & 20 & 2 & 5 & & 11 & 24 & 1 & 0 & \\
\hline Extensive & 18 & 6 & 9 & 0 & 3 & & 5 & 8 & 0 & 5 & \\
\hline \multicolumn{12}{|l|}{ Fibrosis } \\
\hline Absent & 11 & 6 & 5 & 0 & 0 & \multirow[t]{4}{*}{0.603} & 6 & 4 & 1 & 0 & \multirow[t]{4}{*}{0.917} \\
\hline Focal & 72 & 14 & 48 & 1 & 9 & & 13 & 49 & 0 & 10 & \\
\hline Moderate & 43 & 7 & 26 & 1 & 9 & & 8 & 28 & 1 & 6 & \\
\hline Extensive & 34 & 7 & 20 & 0 & 7 & & 7 & 20 & 0 & 7 & \\
\hline \multicolumn{12}{|c|}{ Treatment status ${ }^{\mathrm{a}}$} \\
\hline 1 & 36 & 14 & 11 & 5 & 6 & \multirow[t]{4}{*}{0.032} & 14 & 20 & 1 & 1 & \multirow[t]{4}{*}{0.018} \\
\hline 2 & 22 & 5 & 14 & 1 & 2 & & 11 & 11 & 0 & 0 & \\
\hline 3 & 71 & 36 & 22 & 12 & 1 & & 7 & 59 & 1 & 5 & \\
\hline 4 & 31 & 4 & 12 & 2 & 13 & & 7 & 21 & 0 & 3 & \\
\hline
\end{tabular}

a1, RCHT-resection-no treatment; 2, RCHT-resection-RT/RCHT; 3, no treatment-resection-no treatment; 4, no treatment-resection-RT/RCHT. Adca, adenocarcinoma; Muc, mucinous; RCHT, radiochemotherapy; RT, radiotheraphy.

Another study indicated that the combination of the number of intratumoral CD8-positive T cells with a high level of C-reactive protein $(\mathrm{CRP})$ may possess predictive value for recurrence in CRC patients receiving chemotherapy treatment (23). The present study indicated that local and systemic chronic inflammation was simultaneously observed in $24 \%$ of cases. The majority of the cases $(\sim 73 \%)$ exhibited a predominantly local chronic response (high percentage of TILs and low ALC). Moreover, Turner et al (24) demonstrated the presence of the local chronic response consisting of lymphocytes, plasma cells, macrophages within tumour areas (24). In addition, systemic chronic inflammation was assessed by the expression of neutrophil-to-lymphocyte ratio (NLR) in preoperative blood samples in only $10 \%$ of stage II colon cancer cases (24). The authors of that study further indicated that patients with predominantly local response exhibited the best outcomes, while those with systemic inflammatory response exhibited reduced survival and poor prognosis (24).
The present study demonstrated the association between the combination index of TIL percentage and ALC with clinicopathological features. Patients with low local and systemic inflammatory response exhibited higher tumour growth and larger tumour mass associated with necrosis. Moreover, the patients from group 4 who presented with lymph node metastasis indicated higher percentage of cancer cell invasion beyond the lymph node pouch to the local fat tissue. Wu et al (25) demonstrated that the percentage of TILs and the ALC correlated with local recurrence. Moreover, Xiao et al (26) postulated that the density of $\mathrm{CD}^{+}$lymphocytes in the biopsy materials could be combined with the circulating lymphocyte ratio in order to predict complete response following neoadjuvant chemoradiotherapy in rectal cancer. Similar observations were found in studies conducted on breast cancer $(27,28)$. The present study further indicated that patients with neoadjuvant therapy (status treatment group 1 and 2) exhibited 
Table IV. Correlations between combined parameters of tumor-infiltrating lymphocytes and absolute lymphocyte count obtained after surgery, and clinicopathological features of patients with colorectal cancer $(n=160)$.

\begin{tabular}{|c|c|c|c|c|c|c|c|c|c|c|c|}
\hline \multirow[b]{4}{*}{ Parameter } & \multirow[b]{4}{*}{ No. } & \multicolumn{10}{|c|}{ TILs and absolute lymphocyte count } \\
\hline & & \multicolumn{10}{|c|}{ After surgery } \\
\hline & & \multicolumn{5}{|c|}{ Invasive front } & \multicolumn{5}{|c|}{ Main mass } \\
\hline & & $1, \mathrm{n}$ & $2, \mathrm{n}$ & $3, \mathrm{n}$ & $4, \mathrm{n}$ & P-value & $1, \mathrm{n}$ & $2, \mathrm{n}$ & $3, \mathrm{n}$ & $4, \mathrm{n}$ & P-value \\
\hline \multicolumn{12}{|l|}{ Age, years } \\
\hline$<60$ & 40 & 22 & 12 & 0 & 6 & 0.245 & 21 & 13 & 1 & 5 & 0.545 \\
\hline$\geq 60$ & 120 & 47 & 47 & 1 & 25 & & 47 & 44 & 2 & 27 & \\
\hline \multicolumn{12}{|l|}{ Sex } \\
\hline Female & 64 & 30 & 20 & 0 & 14 & 0.984 & 31 & 20 & 0 & 13 & 0.719 \\
\hline Male & 96 & 39 & 39 & 1 & 17 & & 37 & 37 & 3 & 19 & \\
\hline \multicolumn{12}{|l|}{ Localization } \\
\hline Right-side & 20 & 8 & 7 & 0 & 5 & 0.320 & 10 & 6 & 1 & 3 & 0.438 \\
\hline Transverse & 14 & 2 & 2 & 1 & 9 & & 2 & 2 & 0 & 10 & \\
\hline Left-side & 15 & 3 & 3 & 0 & 9 & & 3 & 2 & 0 & 10 & \\
\hline Sigmoid & 29 & 12 & 7 & 0 & 10 & & 2 & 7 & 0 & 20 & \\
\hline Rectum & 82 & 37 & 30 & 0 & 20 & & 34 & 28 & 0 & 20 & \\
\hline \multicolumn{12}{|c|}{ Tumor growth } \\
\hline Expanding & 133 & 54 & 51 & 1 & 27 & 0.489 & 53 & 49 & 3 & 28 & 0.007 \\
\hline Infiltrate & 27 & 15 & 8 & 0 & 4 & & 15 & 8 & 0 & 4 & \\
\hline \multicolumn{12}{|c|}{ Tumor size, $\mathrm{cm}$} \\
\hline$<2.5$ & 27 & 9 & 12 & 0 & 6 & 0.426 & 8 & 14 & 1 & 4 & 0.031 \\
\hline $2.5-5.0$ & 106 & 48 & 38 & 0 & 19 & & 48 & 35 & 2 & 21 & \\
\hline$>5.0$ & 27 & 12 & 9 & 1 & 6 & & 12 & 8 & 0 & 7 & \\
\hline \multicolumn{12}{|c|}{ Histological type } \\
\hline Muc & 30 & 16 & 12 & 1 & 1 & 0.079 & 16 & 7 & 0 & 7 & 0.056 \\
\hline Adca & 130 & 53 & 47 & 0 & 30 & & 52 & 50 & 3 & 25 & \\
\hline \multicolumn{12}{|c|}{ Mucinous component, $\%$} \\
\hline $10-30$ & 15 & 5 & 5 & 1 & 4 & 0.148 & 5 & 4 & 0 & 6 & 0.081 \\
\hline $31-50$ & 15 & 11 & 2 & 0 & 2 & & 11 & 3 & 0 & 2 & \\
\hline \multicolumn{12}{|l|}{ TNM stage } \\
\hline $1+2$ & 73 & 33 & 24 & 0 & 16 & 0.913 & 33 & 27 & 1 & 12 & 0.651 \\
\hline $3+4$ & 87 & 36 & 35 & 1 & 3 & & 35 & 30 & 2 & 20 & \\
\hline \multicolumn{12}{|c|}{ Grade of malignancies } \\
\hline 2 & 148 & 66 & 54 & 1 & 27 & 0.618 & 65 & 52 & 3 & 28 & 0.806 \\
\hline 3 & 12 & 3 & 5 & 0 & 4 & & 3 & 5 & 0 & 4 & \\
\hline \multicolumn{12}{|l|}{ pT stage } \\
\hline $1+2$ & 65 & 28 & 22 & 0 & 15 & 0.124 & 27 & 24 & 2 & 12 & 0.049 \\
\hline $3+4$ & 95 & 41 & 37 & 1 & 16 & & 41 & 33 & 1 & 20 & \\
\hline \multicolumn{12}{|c|}{ Venous invasion } \\
\hline Absent & 113 & 48 & 40 & 0 & 25 & 0.861 & 48 & 40 & 3 & 22 & 0.300 \\
\hline Present & 46 & 21 & 19 & 1 & 5 & & 20 & 17 & 0 & 9 & \\
\hline \multicolumn{12}{|c|}{ Lymphatic invasion } \\
\hline Absent & 121 & 51 & 44 & 0 & 26 & 0.935 & 51 & 43 & 1 & 26 & 0.879 \\
\hline Present & 38 & 18 & 15 & 1 & 4 & & 17 & 14 & 2 & 5 & \\
\hline Perineural in & & & & & & & & & & & \\
\hline Absent & 143 & 61 & 53 & 1 & 28 & 0.803 & 60 & 52 & 3 & 28 & 0.903 \\
\hline Present & 17 & 8 & 6 & 0 & 3 & & 8 & 5 & 0 & 4 & \\
\hline Lymph node & & & & & & & & & & & \\
\hline Absent & 81 & 42 & 31 & 0 & 8 & 0.788 & 41 & 32 & 2 & 6 & 0.623 \\
\hline Present & 79 & 27 & 28 & 1 & 23 & & 27 & 25 & 1 & 26 & \\
\hline
\end{tabular}


Table IV. Continued.

\begin{tabular}{|c|c|c|c|c|c|c|c|c|c|c|c|}
\hline \multirow[b]{4}{*}{ Parameter } & \multirow[b]{4}{*}{ No. } & \multicolumn{10}{|c|}{ TILs and absolute lymphocyte count } \\
\hline & & \multicolumn{10}{|c|}{ After surgery } \\
\hline & & \multicolumn{5}{|c|}{ Invasive front } & \multicolumn{5}{|c|}{ Main mass } \\
\hline & & $1, \mathrm{n}$ & $2, \mathrm{n}$ & $3, \mathrm{n}$ & $4, \mathrm{n}$ & P-value & $1, \mathrm{n}$ & $2, \mathrm{n}$ & $3, \mathrm{n}$ & $4, \mathrm{n}$ & P-value \\
\hline \multicolumn{12}{|c|}{ Lymph node pouch invasion } \\
\hline Absent & 41 & 12 & 10 & 1 & 18 & 0.037 & 23 & 15 & 0 & 3 & 0.888 \\
\hline Present & 39 & 5 & 23 & 0 & 10 & & 12 & 7 & 2 & 18 & \\
\hline \multicolumn{12}{|c|}{ Distant metastasis } \\
\hline Absent & 143 & 63 & 52 & 1 & 27 & 0.526 & 63 & 51 & 2 & 27 & 0.539 \\
\hline Present & 17 & 6 & 7 & 0 & 3 & & 5 & 6 & 1 & 5 & \\
\hline \multicolumn{12}{|c|}{ Tumor deposits } \\
\hline Absent & 133 & 52 & 51 & 1 & 29 & 0.953 & 52 & 50 & 2 & 29 & 0546 \\
\hline Present & 27 & 16 & 8 & 0 & 3 & & 15 & 7 & 1 & 4 & \\
\hline \multicolumn{12}{|c|}{ Tumor budding } \\
\hline Absent & 94 & 40 & 33 & 1 & 20 & 0.230 & 39 & 34 & 2 & 19 & 0.090 \\
\hline Present & 66 & 29 & 26 & 0 & 11 & & 29 & 23 & 1 & 13 & \\
\hline \multicolumn{12}{|l|}{ Necrosis } \\
\hline Absent & 45 & 17 & 15 & 1 & 12 & 0.201 & 16 & 16 & 1 & 12 & 0.037 \\
\hline Focal & 61 & 26 & 27 & 0 & 8 & & 25 & 24 & 1 & 11 & \\
\hline Moderate & 36 & 15 & 14 & 0 & 7 & & 17 & 15 & 0 & 4 & \\
\hline Extensive & 18 & 11 & 3 & 0 & 4 & & 10 & 2 & 1 & 5 & \\
\hline \multicolumn{12}{|l|}{ Fibrosis } \\
\hline Absent & 11 & 7 & 4 & 0 & 0 & 0.687 & 7 & 3 & 1 & 0 & 0.455 \\
\hline Focal & 72 & 32 & 27 & 1 & 12 & & 32 & 24 & 0 & 16 & \\
\hline Moderate & 43 & 15 & 16 & 0 & 12 & & 16 & 17 & 2 & 8 & \\
\hline Extensive & 34 & 15 & 12 & 0 & 7 & & 13 & 12 & 0 & 19 & \\
\hline \multicolumn{12}{|c|}{ Treatment status ${ }^{\mathrm{a}}$} \\
\hline 1 & 36 & 27 & 3 & 0 & 6 & $<0.001$ & 26 & 3 & 2 & 5 & $<0.001$ \\
\hline 2 & 22 & 17 & 5 & 0 & 0 & & 17 & 5 & 0 & 0 & \\
\hline 3 & 71 & 19 & 41 & 1 & 11 & & 19 & 37 & 1 & 14 & \\
\hline 4 & 31 & 12 & 19 & 0 & 0 & & 12 & 19 & 0 & 0 & \\
\hline
\end{tabular}

${ }^{\mathrm{a}}$ 1, RCHT-resection-no treatment; 2, RCHT-resection-RT/RCHT; 3, no treatment-resection-no treatment; 4, no treatment-resection-RT/RCHT. Adca, adenocarcinoma; Muc, mucinous; RCHT, radiochemotherapy; RT, radiotheraphy.

optimal local and systemic chronic inflammatory response. Unfortunately, the present study contains certain limitations. Initially, the sample size that corresponded to the patients who responded to preoperative treatment was relatively small. In addition, our analysis did not provide complete data regarding the type of chemotherapeutic drugs used and the number of chemotherapy cycles. Despite these limitations, the present study indicated that the measured parameters were associated with tumour progression and neoadjuvant therapy.

The previous study conducted by our group demonstrated that the percentage of stromal TILs present at the invasive tumour front correlated with the histopathological features of tumour progression (17). In the present study, the data demonstrated that approximately half of all patients exhibited a locally advanced tumour with lymph node involvement, whereas the incidence of distant metastases was less common. Therefore, the study group was divided into 3 subgroups including patients without invasion of cancer cells, patients with invasion of cancer cells to lymphatic vessels and local lymph nodes, patients with lack of distant metastasis and patients with invasion of cancer cells to all aforementioned structures. In addition, the current study attempted to select CRC patients whose TILs and lymphocyte count may have an optimal prognostic value. In the current study, the combination index of different parameters (TILs/lymphocyte count/status progression) exhibited the highest diagnostic value in patients of group 4 (high TILS/high lymphocyte count/presence of local or distant metastases). The aforementioned combination of parameters was significantly associated with numerous pathological and clinical variables, such as tumour growth, tumour size, histological type, percentage of mucinous components, TNM stage, venous, lymphatic and perineural invasions, lymph node metastasis, 
Table V. Associations between combined parameters of tumor-infiltrating lymphocytes, absolute lymphocyte count and tumor progression status, and clinicopathological features of patients with colorectal cancer $(n=160)$.

\begin{tabular}{|c|c|c|c|c|c|c|c|c|c|c|c|}
\hline \multirow[b]{3}{*}{ Parameter } & \multirow[b]{3}{*}{ No. } & \multicolumn{10}{|c|}{ TILs, absolute lymphocyte count and tumor progression status } \\
\hline & & \multicolumn{5}{|c|}{ Before surgery } & \multicolumn{5}{|c|}{ After surgery } \\
\hline & & $1, \mathrm{n}$ & $2, \mathrm{n}$ & $3, \mathrm{n}$ & $4, \mathrm{n}$ & P-value & $1, \mathrm{n}$ & $2, \mathrm{n}$ & $3, \mathrm{n}$ & $4, \mathrm{n}$ & P-value \\
\hline \multicolumn{12}{|l|}{ Age, years } \\
\hline$<60$ & 40 & 2 & 12 & 3 & 21 & \multirow[t]{2}{*}{0.112} & 9 & 6 & 13 & 10 & \multirow[t]{2}{*}{0.688} \\
\hline$\geq 60$ & 120 & 11 & 34 & 22 & 37 & & 25 & 21 & 28 & 32 & \\
\hline \multicolumn{12}{|l|}{ Sex } \\
\hline Female & 64 & 15 & 17 & 8 & 25 & \multirow[t]{2}{*}{0.353} & 15 & 8 & 17 & 16 & \multirow[t]{2}{*}{0.966} \\
\hline Male & 96 & 3 & 29 & 17 & 33 & & 19 & 19 & 24 & 26 & \\
\hline \multicolumn{12}{|l|}{ Localization } \\
\hline Right-side & 20 & 3 & 6 & 5 & 8 & \multirow[t]{5}{*}{0.287} & 5 & 5 & 7 & 5 & \multirow[t]{5}{*}{0.864} \\
\hline Transverse & 14 & 1 & 1 & 4 & 4 & & 5 & 14 & 5 & 3 & \\
\hline Left-side & 15 & 1 & 9 & 1 & 3 & & 2 & 4 & 2 & 2 & \\
\hline Sigmoid & 29 & 0 & 3 & 1 & 4 & & 0 & 1 & 4 & 6 & \\
\hline Rectum & 82 & 7 & 26 & 11 & 30 & & 20 & 3 & 20 & 22 & \\
\hline \multicolumn{12}{|l|}{ Tumor growth } \\
\hline Expanding & 133 & 10 & 36 & 21 & 49 & \multirow[t]{2}{*}{0.037} & 25 & 23 & 33 & 37 & \multirow[t]{2}{*}{0.605} \\
\hline Infiltrate & 27 & 3 & 10 & 4 & 9 & & 9 & 4 & 8 & 5 & \\
\hline \multicolumn{12}{|l|}{ Tumor size, $\mathrm{cm}$} \\
\hline$<2.5$ & 27 & 5 & 3 & 4 & 12 & 0.599 & 4 & 4 & 6 & 10 & 0.021 \\
\hline $2.5-5.0$ & 106 & 7 & 35 & 19 & 34 & & 23 & 20 & 29 & 24 & \\
\hline$>5.0$ & 27 & 1 & 9 & 2 & 12 & & 7 & 3 & 6 & 8 & \\
\hline Histological type & & & & & & & & & & & \\
\hline Mucinous & 30 & 1 & 11 & 3 & 14 & 0.001 & 8 & 4 & 9 & 8 & 0.002 \\
\hline Adenocarcinoma & 130 & 12 & 35 & 22 & 44 & & 26 & 23 & 32 & 34 & \\
\hline Mucinous compon & & & & & & & & & & & \\
\hline $10-30$ & 15 & 12 & 6 & 0 & 4 & 0.008 & 3 & 3 & 2 & 2 & 0.013 \\
\hline $31-50$ & 15 & 1 & 29 & 3 & 10 & & 5 & 1 & 7 & 6 & \\
\hline TNM stage & & & & & & & & & & & \\
\hline 1 & 42 & 4 & 15 & 5 & 14 & 0.085 & 13 & 8 & 10 & 8 & $<0.001$ \\
\hline 2 & 31 & 2 & 11 & 1 & 14 & & 7 & 5 & 7 & 9 & \\
\hline 3 & 69 & 5 & 17 & 4 & 26 & & 13 & 12 & 18 & 20 & \\
\hline 4 & 18 & 2 & 3 & 15 & 4 & & 1 & 2 & 6 & 5 & \\
\hline Grade of malignan & & & & & & & & & & & \\
\hline 2 & 148 & 13 & 44 & 23 & 54 & 0.961 & 33 & 26 & 39 & 38 & 0.659 \\
\hline 3 & 12 & 0 & 2 & 2 & 4 & & 1 & 1 & 2 & 4 & \\
\hline pT stage & & & & & & & & & & & \\
\hline 1 & 3 & 0 & 2 & 0 & 1 & 0.770 & 0 & 2 & 1 & 0 & 0.096 \\
\hline 2 & 62 & 6 & 16 & 10 & 22 & & 15 & 9 & 16 & 15 & \\
\hline 3 & 91 & 6 & 27 & 15 & 34 & & 19 & 14 & 24 & 26 & \\
\hline 4 & 4 & 1 & 1 & 0 & 1 & & 0 & 2 & 0 & 1 & \\
\hline Venous invasion & & & & & & & & & & & \\
\hline Absent & 113 & 10 & 35 & 14 & 39 & 0.518 & 24 & 21 & 27 & 26 & $<0.001$ \\
\hline Present & 46 & 3 & 11 & 11 & 19 & & 10 & 6 & 10 & 16 & \\
\hline Lymphatic invasio & & & & & & & & & & & \\
\hline Absent & 121 & 11 & 37 & 15 & 43 & 0.397 & 27 & 21 & 28 & 30 & $<0.001$ \\
\hline Present & 38 & 2 & 9 & 10 & 15 & & 7 & 6 & 13 & 12 & \\
\hline Perineural invasion & & & & & & & & & & & \\
\hline Absent & 143 & 12 & 41 & 22 & 53 & 0.661 & 31 & 24 & 36 & 39 & 0.001 \\
\hline Present & 17 & 1 & 5 & 3 & 5 & & 3 & 3 & 5 & 3 & \\
\hline
\end{tabular}


Table V. Continued.

TILs, absolute lymphocyte count and tumor progression status

\begin{tabular}{|c|c|c|c|c|c|c|c|c|c|c|c|}
\hline \multirow[b]{3}{*}{ Parameter } & \multirow[b]{3}{*}{ No. } & \multirow{2}{*}{\multicolumn{5}{|c|}{ Before surgery }} & \multirow{2}{*}{\multicolumn{5}{|c|}{ After surgery }} \\
\hline & & & & & & & & & & & \\
\hline & & $1, \mathrm{n}$ & $2, \mathrm{n}$ & $3, \mathrm{n}$ & $4, \mathrm{n}$ & P-value & $1, \mathrm{n}$ & $2, \mathrm{n}$ & $3, \mathrm{n}$ & $4, \mathrm{n}$ & P-value \\
\hline \multicolumn{12}{|c|}{ Lymph node metastasis } \\
\hline Absent & 81 & 8 & 31 & 10 & 34 & \multirow{2}{*}{0.196} & 23 & 17 & 23 & 21 & \multirow[t]{2}{*}{$<0.001$} \\
\hline Present & 79 & 5 & 46 & 15 & 24 & & 11 & 10 & 18 & 21 & \\
\hline \multicolumn{12}{|c|}{ Lymph node pouch invasion } \\
\hline Absent & 41 & 10 & 33 & 11 & 40 & \multirow[t]{2}{*}{$<0.001$} & 25 & 19 & 25 & 26 & \multirow[t]{2}{*}{0.006} \\
\hline Present & 39 & 3 & 13 & 14 & 18 & & 9 & 8 & 16 & 16 & \\
\hline \multicolumn{12}{|c|}{ Distant metastasis } \\
\hline Absent & 143 & 11 & 41 & 20 & 56 & \multirow[t]{2}{*}{0.851} & 34 & 19 & 35 & 41 & \multirow[t]{2}{*}{0.218} \\
\hline Present & 17 & 2 & 5 & 5 & 2 & & 0 & 5 & 6 & 1 & \\
\hline \multicolumn{12}{|c|}{ Tumor deposits } \\
\hline Absent & 133 & 9 & 39 & 18 & 51 & \multirow[t]{2}{*}{0.654} & 26 & 23 & 32 & 37 & \multirow[t]{2}{*}{0.001} \\
\hline Present & 27 & 4 & 6 & 7 & 7 & & 7 & 4 & 9 & 4 & \\
\hline \multicolumn{12}{|c|}{ Tumor budding } \\
\hline Absent & 94 & 8 & 24 & 15 & 35 & \multirow[t]{2}{*}{0.459} & 15 & 19 & 29 & 21 & \multirow[t]{2}{*}{0.941} \\
\hline Present & 66 & 5 & 22 & 10 & 23 & & 19 & 8 & 12 & 21 & \\
\hline \multicolumn{12}{|l|}{ Necrosis } \\
\hline Absent & 45 & 3 & 13 & 5 & 16 & \multirow[t]{4}{*}{0.401} & 11 & 7 & 10 & 11 & \multirow[t]{4}{*}{0.042} \\
\hline Focal & 61 & 7 & 18 & 6 & 24 & & 12 & 13 & 14 & 16 & \\
\hline Moderate & 36 & 1 & 11 & 10 & 13 & & 6 & 6 & 11 & 12 & \\
\hline Extensive & 18 & 2 & 4 & 4 & 5 & & 5 & 1 & 6 & 3 & \\
\hline \multicolumn{12}{|l|}{ Fibrosis } \\
\hline Absent & 11 & 2 & 24 & 4 & 5 & \multirow[t]{4}{*}{0.365} & 2 & 1 & 5 & 3 & \multirow[t]{4}{*}{0.294} \\
\hline Focal & 72 & 5 & 11 & 9 & 27 & & 19 & 10 & 17 & 20 & \\
\hline Moderate & 43 & 5 & 11 & 6 & 17 & & 6 & 9 & 11 & 12 & \\
\hline Extensive & 34 & 3 & 0 & 6 & 9 & & 7 & 7 & 8 & 7 & \\
\hline \multicolumn{12}{|c|}{ Treatment status ${ }^{\mathrm{a}}$} \\
\hline 1 & 36 & 12 & 6 & 16 & 2 & \multirow[t]{4}{*}{0.396} & 2 & 12 & 5 & 17 & 0.007 \\
\hline 2 & 22 & 5 & 12 & 5 & 0 & & 14 & 2 & 2 & 4 & \\
\hline 3 & 71 & 45 & 20 & 5 & 1 & & 25 & 20 & 11 & 15 & \\
\hline 4 & 31 & 23 & 2 & 2 & 4 & & 4 & 12 & 3 & 12 & \\
\hline
\end{tabular}

${ }^{\mathrm{a}}$ 1, RCHT-resection-no treatment; 2, RCHT-resection-RT/RCHT; 3, no treatment-resection-no treatment; 4, no treatment-resection-RT/RCHT. Adca, adenocarcinoma; Muc, mucinous; RCHT, radiochemotherapy; RT, radiotheraphy.

cancer cell invasion beyond the lymph node pouch, tumour deposits and incidence of necrosis. It is important to note that the findings regarding the examined parameters obtained following surgery exhibited the highest diagnostic value.

In light of these observations, the present study demonstrated that the investigation of local and systemic chronic inflammation was associated with tumour progression of CRC patients. Due to this fact, the diagnosis and prognosis of CRC patients should be undertaken on the basis of numerous local and systemic factors.

\section{Acknowledgements}

Not applicable.

\section{Funding}

No funding was received.

\section{Availability of data and materials}

All data generated or analysed during this study are included in this published article.

\section{Authors' contributions}

KJ collected data, performed analysis, wrote the paper, reviewed the literature, acquired the data and contributed to manuscript drafting. MK analysed and interpreted the 
pathological examination and approved the final version of the article. WF and KL collected and analysed data, and approved the final version of the article. MG wrote the paper, reviewed the literature, acquired the data and contributed to manuscript drafting. All authors read and approved the final manuscript.

\section{Ethics approval and consent to participate}

The study was performed in conformity with the Declaration of Helsinki for Human Experimentation. Written informed consent was not required, and informed consent included an opt-out clause approved by the Medical Ethics Committee. The protocol was approved by the Bioethics Committee of the Medical University of Bialystok (NoR-I-002/353/2016).

\section{Patient consent for publication}

Not applicable.

\section{Competing interests}

The authors declare that they have no competing interests.

\section{References}

1. Ando K, Hamada K, Watanabe M, Ohkuma R, Shida M, Onoue R, Kubota Y, Matsui H, Ishiguro T, Hirasawa Y, et al: Plasma levels of soluble PD-L1 correlate with tumor regression in patients with lung and gastric cancer treated with immune checkpoint inhibitors. Anticancer Res 39: 5195-5201, 2019.

2. Badran YR, Cohen JV, Brastianos PK, Parikh AR, Hong TS and Dougan M: Concurrent therapy with immune checkpoint inhibitors and $\mathrm{TNF} \alpha$ blockade in patients with gastrointestinal immune-related adverse events. J Immunother Cancer 7: 226 , 2019.

3. Fan Y and Moon JJ: Nanoparticle drug delivery systems designed to improve cancer vaccines and immunotherapy. Vaccines (Basel) 3: 662-685, 2015

4. Xiong Y, Wang Y and Tiruthani K: Tumor immune microenvironment and nano-immunotherapeutics in colorectal cancer. Nanomedicine 21: 102034, 2019.

5. Compton CC: Colorectal carcinoma: Diagnostic, prognostic, and molecular features. Mod Pathol 16: 376-388, 2003.

6. Guinney J, Dienstmann R, Wang X, de Reyniès A, Schlicker A, Soneson C, Marisa L, Roepman P, Nyamundanda G, Angelino P, et al: The consensus molecular subtypes of colorectal cancer. Nat Med 21: 1350-1356, 2015.

7. Le DT, Uram JN, Wang H, Bartlett BR, Kemberling H, Eyring AD, Skora AD, Luber BS, Azad NS, Laheru D, et al: PD-1 blockade in tumors with mismatch-repair deficiency. N Engl J Med 372: 2509-2520, 2015.

8. Norton SE, Ward-Hartstonge KA, Taylor ES and Kemp RA: Immune cell interplay in colorectal cancer prognosis. World J Gastrointest Oncol 7: 221-232, 2015.

9. Laghi L, Bianchi P, Miranda E, Balladore E, Pacetti V, Grizzi F, Allavena P, Torri V, Repici A, Santoro A, et al: $\mathrm{CD}^{+}$cells at the invasive margin of deeply invading (pT3-T4) colorectal cancer and risk of post-surgical metastasis: A longitudinl study. Lancet Oncol 10: 877-884, 2009.

10. Bindea G, Mlecnik B, Tosolini M, Kirilovsky A, Waldner M, Obenauf AC, Angell H, Fredriksen T, Lafontaine L, Berger A, et al: Spatiotemporal dynamics of intratumoral immune cells reveal the immune landscape in human cancer. Immunity 39: 782-795, 2013.

11. Tanio A, Saito H, Uejima C, Takaya S, Yamamoto M, Tokuyasu N, Sakamoto T, Honjo S, Ashida K and Fujiwara Y: A prognostic index for colorectal cancer based on preoperative absolute lymphocyte, monocyte, and neutrophil counts. Surg Today 49 245-253, 2019.
12. Kozak MM, von Eyben R, Pai JS, Anderson EM, Welton ML, Shelton AA, Kin C, Koong AC and Chang DT: The prognostic significance of pretreatment hematologic parameters in patients undergoing resection for colorectal cancer. Am J Clin Oncol 4: 405-412, 2017.

13. Yang L, He W, Kong P, Jiang C, Yang Q, Xie Q and Xia LP: Clinical baseline and prognostic difference of platelet lymphocyte ratio (PLR) in right-sided and let-sided colon cancers. BMC Cancer 17: 873, 2017.

14. Hamilton SR and Aaltonen LA: Tumors of the colon and rectum. In: World Health Organization Classification of Tumors. Pathology and Genetics of Tumours of the Digestive System. Lyon, IARC Press, pp103-104, 2000.

15. Lin Q, Wei Y, Ren L, Zhong Y, Qin C, Zheng P, Xu P, Zhu D, $\mathrm{Ji} \mathrm{M}$ and Xu J: Tumor deposit is a poor prognostic indicator in patients who underwent simultaneous resection for synchronous colorectal liver metastases. Onco Targets Ther 8: 233-240, 2015.

16. Therasse P, Arbuck SG, Eisenhauer EA, Wanders J, Kaplan RS, Rubinstein L, Verweij J, Van Glabbeke M, van Oosterom AT, Christian MC and Gwyther SG: New guidelines to evaluate the response to treatment in solid tumors. J Natl Cancer Inst 92: 205-216, 2000.

17. Jakubowska K, Kisielewski W, Kańczuga-Koda L, Koda M and Famulski W: Stromal and intraepithelial tumour-infiltrating lymphocytes in colorectal carcinoma. Oncol Lett 14: 6421-6432, 2017.

18. Salgado R, Denkert C, Demaria S, Sirtaine N, Klauschen F, Pruneri G, Wienert S, Van den Eynden G, Baehner FL, Penault-Llorca F, et al: The evaluation of tumour-infiltrating lymphocytes (TILs) in breast cancer: Recommendations by an International TILs working group 2014. Ann Oncol 26: 259-271, 2015.

19. Galon J, Pagès F, Marincola FM, Angell HK, Thurin M, Lugli A, Zlobec I, Berger A, Bifulco C, Botti G, et al: Cancer classification using the Immunoscore: A worldwide task force. J Transl Med 10: 205, 2012.

20. Mlecnik B, Tosolini M, Kirilovsky A, Berger A, Bindea G, Meatchi T, Bruneval P, Trajanoski Z, Fridman WH, Pagès F and Galon J: Histopathologic-based prognostic factors of colorectal cancers are associated with the state of the local immune reaction. J Clin Oncol 29: 610-618, 2011

21. Lam M, Tie J, Lee B, Desai J, Gibbs P and Tran B: Systemic inflammation-impact on tumor biology and outcomes in colorectal cancer. J Clin Cell Immunol 6: 377, 2015.

22. Park JH, Powell AG, Roxburgh CS, Horgan PG, McMillan DC and Edwards J: Mismatch repair status in patients with primary operable colorectal cancer: Associations with the local and systemic tumour environment. Br J Cancer 114: 562-570, 2016.

23. Mori K, Toiyama Y, Saigusa S, Fujikawa H, Hiro J, Kobayashi M, Ohi M, Araki T, Inoue Y, Tanaka K, et al: Systemic analysis of predictive biomarkers for recurrence in colorectal cancer patients treated with curative surgery. Dig Dis Sci 60: 2477-2487, 2015.

24. Turner N, Wong HL, Templeton A, Tripathy S, Whiti Rogers T, Croxford M, Jones I, Sinnathamby M, Desai J, Tie J, et al: Analysis of local chronic inflammatory cell infiltrate combined with systemic inflammation improves prognostication in stage II colon cancer independent of standard clinicopathologic criteria. Int J Cancer 138: 671-678, 2016.

25. Wu B, Zhao S, Sheng Y, Ren L and Song G: The prognostic value of combining the $\mathrm{CD} 8^{+}$lymphocyte density and the circulating lymphocyte ratio in circumferential resection margin biopsy in rectal cancer. Medicine (Baltimore) 97: e11972, 2018.

26. Xiao B, Peng J, Zhang R, Xu J, Wang Y, Fang Y, Lin J, Pan Z and $\mathrm{Wu} X$ : Density of CD8+ lymphocytes in biopsy samples combined with the circulating lymphocyte ratio predicts pathologic complete response to chemoradiotherapy for rectal cancer. Cancer Manag Res 9: 701-708, 2017.

27. Afghahi A, Purington N, Han SS, Desai M, Pierson E, Mathur MB, Seto T, Thompson CA, Rigdon J, Telli ML, et al: Higher absolute lymphocyte counts predict lower mortality from early-stage triple-negative breast cancer. Clin Cancer Res 24: 2851-2858, 2018.

28. Lee KH, Kim EY, Yun JS, Park YL, Do SI, Chae SW and Park $\mathrm{CH}$ : The prognostic and predictive value of tumor-infiltrating lymphocytes and hematologic parameters in patients with breast cancer. BMC Cancer 18: 938, 2018.

This work is licensed under a Creative Commons Attribution-NonCommercial-NoDerivatives 4.0 International (CC BY-NC-ND 4.0) License. 